on the moral permissibility of honour killings as they do on the linguistic grammaticality of well-formed Urdu sentences.

These differences call into question how much insight the research programme developed by linguists can provide into morality. For instance, some arguments for linguistic innateness are based on assumptions about the generative nature of language; these might not export well to the moral domain. In fairness, though, it might be that nobody has found

\title{
Evidence for evolution
}

\section{The Making of the Fittest: DNA and the Ultimate Forensic Record of Evol ution by Sean B. Carroll}

W. W. Norton: 2006.301 pp. $\$ 25.95$

\section{Brian Charlesworth}

Sean Carroll begins his excellent book The Making of the Fittest by pointing out that about $50 \%$ of the American public doubt the truth of darwinian evolution, yet accept other aspects of biological science, such as the use of DNA in forensics. His aim is to use evidence from modern research on DNA to convince the general reader of "the case for biological evolution as the basis for life's diversity, beyond any reasonable doubt". He deliberately does not introduce any of the standard evidence for evolution as a historical process, and only briefly describes the use of DNA sequence data to reconstruct phylogenies. Instead, he uses a series of examples intended to provide compelling evidence for the basic processes involved in evolutionary change, with particular emphasis on mutation and natural selection.

The first example involves the extraordinary icefish of the Antarctic, which have lost their red blood cells and allowed their haemoglobin genes to decay. Carroll shows how this can be interpreted as an adaptive response to life in very cold water, with its high solubility of oxygen in water and high blood viscosity. There follows an exposition of Darwin's ideas about natural selection. Next comes a good but simplified account of the standard theory of selection on single mutations that enhance fitness, these sorts of deep parallels because, before tures of language, the very idea of an innate moral faculty is well worth investigating. Linguists have been exploring this idea for more than 50 years, in the study of morality, we are just getting started.

Paul Bloom and lzzat Jarudiare in the Department of Psychology, Yale University, New Haven, Connecticut 06520-8205, USA. Hauser, nobody had really looked. Moreover, even if morality lacks certain interesting fea- showing that these can spread to high frequencies in times that are trivially short compared with the geological record. Carroll then applies these results to the way that a species of desert-living mouse has adapted to spatial differences in the colour of the ground, right down to the mutational changes that lead to darker coat colour.

Carroll illustrates the power of natural selection to generate evolutionary novelties by discussing duplications of the opsin genes involved in vertebrates' colour vision. Examples of genes and genomes that decay when their function is no longer maintained by natural selection illustrate how ${ }^{\alpha}$ selection acts is done well, although the tone is sometimes gratingly folksy, and there is some unevenness in the level of knowledge assumed (nanometres and natural logarithms are used without definition, for example). The explanations are clear and easy to follow, and the level of factual accuracy is very high, although effective population size is incorrectly used instead of population size in the book's only equation.

Carroll also turns his attention to irrational views on a variety of topics, including the genetics of Trofim Lysenko, chiropractic 'medicine', and opposition to vaccination. This paves the way for a discussion of disbelief in evolution, illustrated with some remarkable quotations from US anti-evolutionists. I am stunned by the ability of people to accept the absurd and discount the rational. Carroll seems confident that the mainstream religions do not reject evolution, but he fails to mention Islam, for which this is far from clear. He quotes with approval a statement by Pope John Paul II on evolution, but does not refer to Cardinal Christoph Schönborn's anti-darwinian diatribe in The New York Times on 7 July 2005. Carroll's final chapter warns of the dangers arising from climate change and the overexploitation of natural resources, where scientific advice is often ignored by governments because of economic considerations.

As Carroll rightly concludes: ${ }^{\alpha} U$ nderstanding and accepting evolution is a matter of adhering to the scientific process." It is extremelyimportant for scientists to fight the idea that evolution can be separated from the rest of science simply because of its unpalatable implications for traditional religious accounts of human origins. We have to insist on the fact that scientific conclusions are based purely on the study of nature, without reference to religious or other authority.

Carroll's book will certainly help the public to understand evoonly in the present, and not as an engineer or designer".

A favourite ploy of creationists is to accept the possibility of small-scale evolutionary change by darwinian means, but to deny that this has any relevance to the evolution of complex structures or new species. Carroll does not discuss how new species evolve, but he examines the problem of complexity using Darwin's example of the eye, bringing in recent results on the molecular basis of eye formation. All this lution more clearly, but rational arguments are unfortunately unlikely to persuade those whose beliefs come from prior authority, whether represented by a fatwa, an encyclical, or the first chapter of Genesis. Wider public understanding of the nature of scientific evidence in general is urgently needed.

Brian Charlesworth is at the Institute of

Evolutionary Biology, School of Biological

Sciences, University of Edinburgh,

Edinburgh EH9 2BR, UK. 